\title{
A Bayesian kriging model for estimating residential exposure to air pollution of children living in a high-risk area in Italy
}

\author{
Ana M. Vicedo-Cabrera ${ }^{1}$, Annibale Biggeri ${ }^{2,3}$, Laura Grisotto ${ }^{2,3}$, Fabio Barbone ${ }^{4}$, Dolores \\ Catelan ${ }^{2,3}$ \\ ${ }^{1}$ Center for Public Health Research (CSISP) - FISABIO, Valencia, Spain; ${ }^{2}$ Biostatistics Unit, ISPO Cancer \\ Prevention and Research Institute, Florence, Italy; ${ }^{3}$ Department of Statistics, Informatics, Applications "G. \\ Parenti”, University of Florence, Florence, Italy; ${ }^{4}$ Institutes of Hygiene and Epidemiology, DPMSC, University \\ of Udine, Udine, Italy
}

\begin{abstract}
A core challenge in epidemiological analysis of the impact of exposure to air pollution on health is assessment of the individual exposure for subjects at risk. Geographical information systems (GIS)-based pollution mapping, such as kriging, has become one of the main tools for evaluating individual exposure to ambient pollutants. We applied universal Bayesian kriging to estimate the residential exposure to gaseous air pollutants for children living in a high-risk area (MilazzoValle del Mela in Sicily, Italy). Ad hoc air quality monitoring campaigns were carried out: 12 weekly measurements for sulphur dioxide $\left(\mathrm{SO}_{2}\right)$ and nitrogen dioxide $\left(\mathrm{NO}_{2}\right)$ were obtained from 21 passive dosimeters located at each school yard of the study area from November 2007 to April 2008. Universal Bayesian kriging was performed to predict individual exposure levels at each residential address for all 6- to 12-years-old children attending primary school at various locations in the study area. Land use, altitude, distance to main roads and population density were included as covariates in the models. A large geographical heterogeneity in air quality was recorded suggesting complex exposure patterns. We obtained a predicted mean level of $25.78( \pm 10.61) \mu \mathrm{g} / \mathrm{m}^{3}$ of $\mathrm{NO}_{2}$ and $4.10( \pm 2.71) \mu \mathrm{g} / \mathrm{m}^{3}$ of $\mathrm{SO}_{2}$ at 1,682 children's residential addresses, with a normalised root mean squared error of $28 \%$ and $25 \%$, respectively. We conclude that universal Bayesian kriging approach is a useful tool for the assessment of realistic exposure estimates with regard to ambient pollutants at home addresses. Its prediction uncertainty is highly informative and can be used for both designing subsequent campaigns and for improved modelling of epidemiological associations.
\end{abstract}

Keywords: Bayesian kriging, geographical information system, exposure assessment, environmental epidemiology, Italy.

\section{Introduction}

Assessment of individual exposure for subjects at risk is the core challenge in epidemiological analysis of the impact of exposure to air pollution. In most epidemiological studies, evaluation of this association has relied on simple measures, e.g. with regard to exposure to pollution from road traffic: proximity based on questionnaire responses, self-reported traffic density, distance to busy streets, etc. (Venn et al., 2001; Heinrich et al., 2004; McConnell et al., 2006; Brunekreef et al., 2009). However, this approach has been strongly criticised. For example, Kuehni et al. (2006) demonstrated that reporting bias could explain some (sometimes even all) association between reported traffic exposure and disease. Likewise, exposure

\footnotetext{
Corresponding author:

Ana M. Vicedo-Cabrera

Center for Public Health Research (CSISP) - FISABIO

Av. Cataluña 21, 46020 Valencia, Spain

Tel. +34 96 192-5941; Fax +3496 192-5703

E-mail: vicedo_ana@gva.es
}

estimates at the spatially aggregated level have been widely used. This approach rests on values from a single stationary monitor or average concentrations of a limited number of monitoring stations within each community (Anderson et al., 2010). However, this does not capture spatial heterogeneity in exposure to air pollution. Also, it may lead to inaccuracies such as the misclassification bias, which possibly underestimates the effects of air pollution (Thomas et al., 1993; Peng and Bell, 2010), as they do not account for individual-level exposure (Bell, 2006).

The most desirable method to estimate exposure would be to measure air pollution levels of each study subject individually. Although this can be performed directly through personal monitoring (Liu et al., 1993; Scapellato et al., 2009), the feasibility of measuring personal exposure is problematic due to high cost and difficulties related to the necessity for large numbers of people (the study subjects) to carry personal monitors for long periods of time. Geographical information systems (GIS) can be used to minimize the potential problems of assessing exposure at the aggregate level, and this approach allows more precise estimations of 
exposure to air pollution and exposures for time periods and/or locations for which monitoring data are not available. By providing a means of capturing and linking spatial data within a single geographical structure, GIS improves data integration and consistency. Equally, by providing a means of combining pollution and population data, GIS also provides explicit tools for assessing exposure (Briggs, 2005). In fact, GISbased pollution mapping has become one of the main tools for exposure assessment of ambient pollutants and, coupled with interpolation techniques, such as inverse distance weighting and kriging as well as land use regression (LUR) modelling, are now often used for the estimation of individual exposure (Briggs, 2005; Hoek et al., 2008).

Kriging has predictive power for unmeasured locations by estimating the parameters of a model of the spatial surface of concentrations of air pollutants according to observed data. The data are assumed to be generated from a stochastic process, which is split into a trend component and an error component. This trend is constant but unknown in ordinary kriging, whereas universal kriging uses secondary data (predictor variables such as topography or land use variables) to characterise the spatial trend of the dependent variable. Bayesian specifications of the ordinary and universal kriging models are very flexible even if computationally intensive (Banerjee et al., 2006).

One of the advantages of kriging with respect to other deterministic interpolation techniques (e.g. LUR) is that it provides measures of uncertainty, which come in the form of standard errors of the estimates at unsampled sites (Cressie, 2002). For example, LUR models are used to predict at unknown locations in two steps. First, estimates of regression coefficients, and related standard errors, for given covariates at known locations are obtained. Second, the estimated regression coefficients, but not their uncertainties, are used to obtain prediction at the unknown location. We thus have uncertainty only at the known location. Kriging, in contrast, uses information on spatial dependence and implicitly provides uncertainty estimation at unknown locations. Even so, the number of published applications using kriging remains remarkably small (Pikhart et al., 1997; Tolbert et al., 2000; Chan et al., 2009; Son et al., 2010; Esplugues et al., 2011).

In order to describe an accurate and precise pollution surface by kriging, a relatively dense network of measurement sites is required. Such a network of monitoring stations rarely exists and is frequently far from being representative of entire study areas. The monitors of existing networks are seldom regularly distributed and the surfaces interpolated from these sites consequently tend to be strongly biased and almost invariably overly smooth (Briggs, 2005). Ad hoc monitoring campaigns, permitting an adequate network of air pollution monitoring, would be of high interest as they would produce better predictive surfaces. In the present study, we applied a Bayesian kriging model using data from dosimeters located in a priori selected monitoring sites in the study area with the aim of estimating the residential exposure of children living in an area of high risk for gaseous air pollution (Milazzo-Valle del Mela in Sicily).

\section{Materials and methods}

\section{Study area and design}

The area of Milazzo-Valle del Mela, located in northern Sicily, Italy (Fig. 1), has been recognised as a polluted site of national concern. Research in this area is included in the group of studies run under the World Health Organization (WHO) project on high-risk areas of the Sicilian region. The presence of an oil refinery, a petrochemical plant, a large oil-fuelled power plant, small industries and foundries along with the busy seaport of Milazzo and the Palermo-Messina highway puts this relatively small area at particularly high risk for the development of respiratory diseases. In April and May 2007, all 6- to 12-years-old children attending the 21 primary schools of the study area (the municipalities of Condrò, Gualtieri Sicaminò, Milazzo, Pace del Mela, San Filippo del Mela, San Pier Niceto and Santa Lucia del Mela) were enrolled in a cross-sectional survey. This study was carried out with the aim of evaluating the prevalence of respiratory disorders among children population and the association with known risk factors, including air pollution.

\section{Exposure assessments}

In the Milazzo-Valle del Mela investigation, ambient air quality was assessed by ad hoc monitoring campaigns. Twenty-one passive dosimeters were located across the study area (one monitor in each schoolyard). Sulphur dioxide $\left(\mathrm{SO}_{2}\right)$ and nitrogen dioxide $\left(\mathrm{NO}_{2}\right)$ were continuously measured for 7-day periods every 2 weeks from November 2007 to April 2008. At the end of the campaign period, 12 weekly averages were calculated for each dosimeter and gaseous pollutant. The sampler was in accordance to European standards CEN. The analyses were done by Passam Laboratory for environmental analysis (EN 45001 1996; ISO/IEC 17025 2001). 


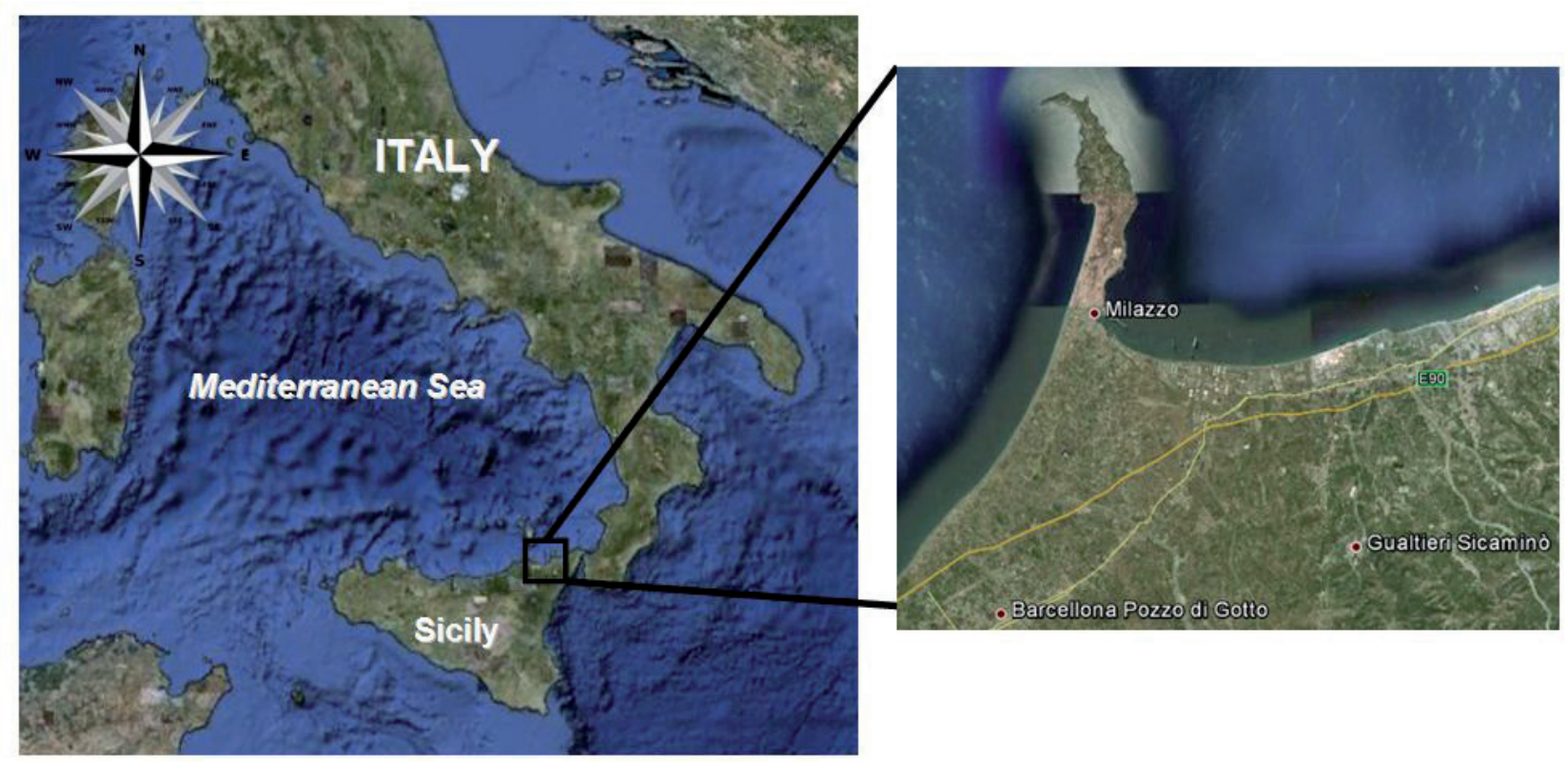

Fig. 1. Study area: Milazzo-Valle del Mela, Sicily, Italy.

\section{Geographical information system}

A GIS for the study area was developed using ArcGIS software, version 9 (ESRI Inc.; Redlands, USA) with data-layers for elevation, slope and aspect of the study area at a $40 \mathrm{~m}$ spatial resolution (obtained from a digital elevation model (DEM) sourced at the Cartographic Office of the Regione Campania); land use (Corinne Land Cover); population density (LandScan 2010 Global Population Database) and a road map (TeleAtlas). To better characterise the observed spatial trend of pollutants concentration, some selected covariates were introduced in the model. The selection of covariates was done outside the kriging model through automatic stepwise regression and based on a review of the literature for the considered pollutants. The final set of selected covariates included altitude above the mean sea level (MSL); distance to main roads; population density and land use. The covariates were calculated as the proportion of surface area over a $500 \mathrm{~m}$ buffer zone (industrial, urban and suburban land cover). Information regarding all these covariates (the same for both pollutants) was obtained for each residential address and dosimeter location. A sensitivity analysis (data not shown) was conducted using different approaches to covariates selection.

All residential addresses of the study subjects, along with the location of the passive dosimeters at all schools, were geocoded using ArcGIS according to the addresses provided in a questionnaire (i.e. each location was converted into $X / Y$ coordinates using the Universal Transverse Mercator System, zone 33S). To be correctly geocoded, this software requires a database of properly-formed addresses and a reference database of streets or road layout of the study area.

\section{Bayesian kriging model}

A universal Bayesian kriging approach was adopted to estimate the ambient pollutant concentration at the residential address of each child. For this purpose, a dosimeter-specific average concentration of $\mathrm{NO}_{2}$, and median value for $\mathrm{SO}_{2}$ was calculated using the 127 day measurements obtained during the campaign period. In the latter case, we used the median instead of the mean in order to obtain estimates of background $\mathrm{SO}_{2}$ levels since the mean values of this pollutant are usually influenced by occasional peaks. In detail, we assumed that $Y$, the vector of the logarithm of the observed value is distributed as:

$$
Y \sim \operatorname{MVN}(\mu, \Sigma)
$$

where MVN is the multivariate normal likelihood for $\mathrm{Y}$ of $\mathrm{SO}_{2}$ or $\mathrm{NO}_{2}$ concentrations observed at passive dosimeters locations. We assumed that the mean is dependent of a series of covariates $X_{i}\left(\mu_{i}=\beta_{o}+\beta_{i} x_{i}\right)$. The $a$ priori distributions for $\beta$ o and $\beta i$ are weakly informative. We further assumed a spatial exponential 
Gaussian parametric form for the elements of the correlation matrix $\Sigma_{i, j}=\mathrm{f}\left(d_{i, j}, \kappa, \phi\right)$. This corresponds to assume:

$$
\mathrm{f}\left(d_{i, j}, \kappa, \phi\right)=\exp \left[-\left(\phi d_{i j}\right)^{k}\right]
$$

where $d_{i j}$ is the distance between the pairs of dosimeters $i$ and $j$, while $\phi>0$ controls the rate of decline of correlation by distance and $k(0 ; 2)$ controls the amount of spatial smoothing. The parameter $\kappa$ was fixed to 1 , and $\phi$ was chosen to get almost zero correlation between any pair of points at the maximum distance $(9.32 \mathrm{~km})$ and almost one at the minimum distance $(0.10 \mathrm{~km})$ as discussed by Banerjee et al. (2006).

The accuracy of the kriging model was evaluated by a cross-validation procedure (Hastie et al., 2009). The normalised root mean square error (NRMSE) was used to describe the quality of predictions by the interpolation method and similarity between the observed and predicted values. All computations were made by Markov Chain Monte Carlo (MCMC) using the WinBUGS software (Lunn et al., 2000). We ran two independent chains and checks for achieved convergence of the algorithm following Gelman and Rubin (1992). According to this, convergence was achieved after 5,000 iterations. We decided to run 50,000 iterations and to store the last 20,000 iterations for estimation (Gelman and Rubin, 1992).

\section{Results}

\section{Description of the empirical data}

In general, a large geographical heterogeneity in air quality was recorded suggesting complex exposure patterns. Regarding $\mathrm{NO}_{2}$, the highest mean levels during the study period were registered in the dosimeters located in the Archi area (dosimeters nos. 11 and 12), being most of the weekly averages over $40 \mu \mathrm{g} / \mathrm{m}^{3}$, and maximums near $60 \mu \mathrm{g} / \mathrm{m}^{3}$ (Fig. 2). Both dosimeters were located near the busy Palermo-Messina highway and the industrial area of Milazzo. The dosimeters located in the inner parts of the region (nos. 10, 18, 20 and 21) and the one of the Capo school (no. 3), which is located in the apical region of the Cape of Milazzo, showed the lowest mean values for the study period due to their location far away from the main sources of pollution.

The registered levels of $\mathrm{SO}_{2}$ were less stable compared to $\mathrm{NO}_{2}$, with concentration peaks $>20 \mu \mathrm{g} / \mathrm{m}^{3}$ in almost every dosimeter. A maximum peak $>100 \mu \mathrm{g} / \mathrm{m}^{3}$ was observed in dosimeter no. 2 located in the Piaggia School in the city of Milazzo (Fig. 3). The highest peaks were registered in the dosimeters located around the industrial area. As expected, the mean value in each dosimeter was highly influenced by several peaks, with large differences between this and the median value

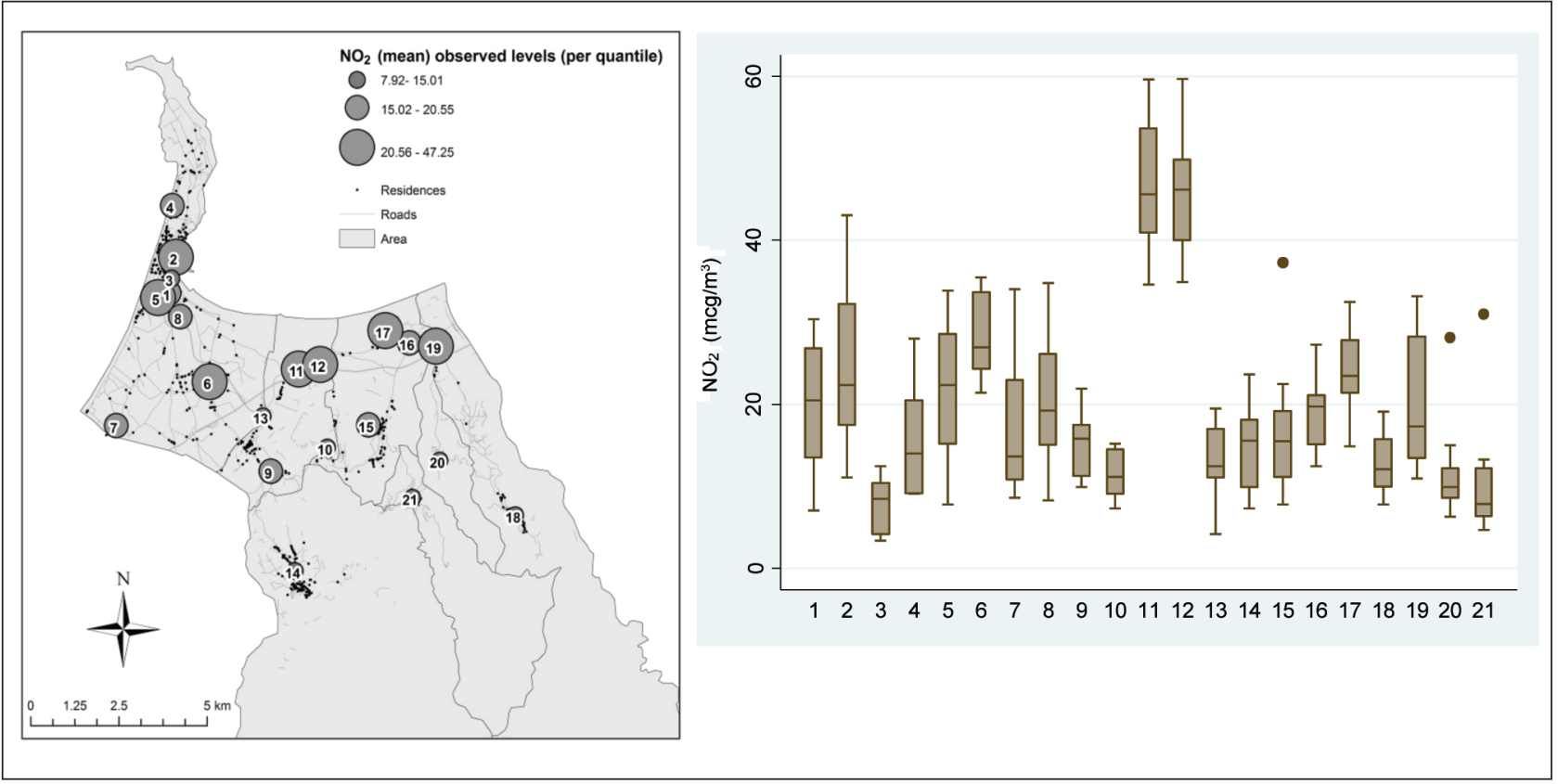

Fig. 2. Study area with the location of the main roads, children residences and the 21 dosimeters (labeled according to $\mathrm{NO}_{2}$ mean levels) (left). Multiple Boxplot of the observed exposure levels of $\mathrm{NO}_{2}$ per study monitor (right). Numbered according to table 1. Milazzo-Valle del Mela area, November 2007-April 2008. 


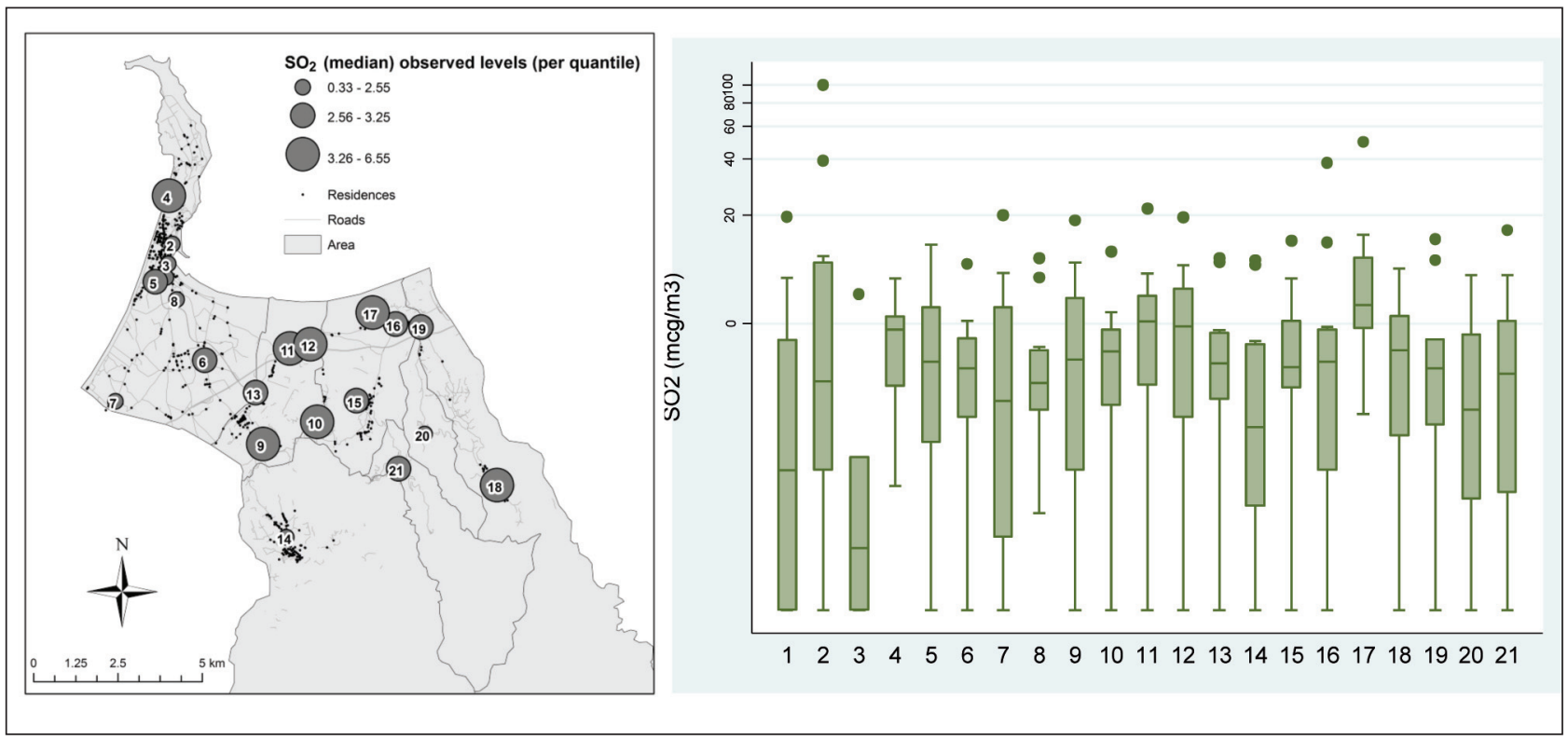

Fig. 3. Study area with the location of the main roads, children residences and the 21 dosimeters (labeled according to $\mathrm{SO}_{2}$ median levels) (left). Multiple Boxplot of the observed exposure levels of $\mathrm{SO}_{2}$ per study monitor (logarithmic scale) (right). Numbered according to table 1. Milazzo-Valle del Mela area, November 2007-April 2008.

(Table 1). If we just consider this latter (the median) as a summary statistic of the background level of $\mathrm{SO}_{2}$, a similar pattern to the one of $\mathrm{NO}_{2}$ was observed, with lower median concentrations registered in the dosimeters located in the inner area (nos. 14, 18 and 20) and the one of the Capo school (no. 3), and higher median levels in those situated in the eastern zone near the industrial area (nos. 11, 12 and 17) (Fig. 3). It should be considered that the most polluted areas were also the most populated ones, especially the area of the city of Milazzo. The correlation between the $\mathrm{NO}_{2}$ mean level and the $\mathrm{SO}_{2}$ median observed value was moderate (Spearman correlation coefficient 0.604 at $95 \%$ confidence interval $(\mathrm{CI})=0.233,0.821)$.

Table 1. Descriptive statistics for the observed exposure levels of $\mathrm{NO}_{2}$ and $\mathrm{SO}_{2}$ in the Milazzo-Valle del Mela area of Sicily in the period November 2007-April 2008.

\begin{tabular}{|c|c|c|c|c|c|c|c|c|c|c|}
\hline \multirow{2}{*}{ Places monitored } & \multicolumn{5}{|c|}{$\mathrm{NO}_{2}$} & \multicolumn{5}{|c|}{$\mathrm{SO}_{2}$} \\
\hline & Mean & $\mathrm{SD}^{*}$ & Median & $\operatorname{Max}$ & Min & Mean & $\mathrm{SD}^{*}$ & Median & Max & Min \\
\hline 1. Primary school Sacro Cuore & 19.95 & 8.08 & 20.50 & 30.40 & 7.06 & 3.48 & 5.75 & 0.85 & 19.5 & 0.15 \\
\hline 2. Primary school Piaggia & 25.09 & 9.69 & 22.35 & 43.10 & 11.10 & 14.47 & 29.06 & 2.55 & 100.00 & 0.15 \\
\hline 3. Primary school Capo & 7.92 & 3.60 & 8.50 & 12.50 & 3.40 & 1.58 & 2.92 & 0.33 & 7.50 & 0.15 \\
\hline 4. Primary school Tono & 15.80 & 7.31 & 14.00 & 28.00 & 9.10 & 4.60 & 2.91 & 4.85 & 9.10 & 0.70 \\
\hline 5. Primary school San Giovanni & 21.71 & 8.16 & 22.35 & 33.90 & 7.80 & 4.27 & 4.06 & 3.25 & 13.90 & 0.15 \\
\hline 6. Primary school Grazia & 28.30 & 4.97 & 26.95 & 35.50 & 21.40 & 3.39 & 2.88 & 3.00 & 10.90 & 0.15 \\
\hline 7. Primary school Bastione & 17.04 & 8.02 & 13.65 & 34.08 & 8.60 & 4.43 & 5.81 & 2.00 & 19.90 & 0.15 \\
\hline 8. Primary school Ciantro & 20.55 & 8.14 & 19.25 & 34.80 & 8.30 & 3.76 & 3.31 & 2.50 & 11.70 & 0.50 \\
\hline 9. Primary school S. Filippo & 15.16 & 3.70 & 15.80 & 21.90 & 9.90 & 5.00 & 5.54 & 3.35 & 18.60 & 0.15 \\
\hline 10. Primary school Cattafi & 11.50 & 2.96 & 11.15 & 15.20 & 7.30 & 4.01 & 3.27 & 3.70 & 12.70 & 0.15 \\
\hline 11. Primary school Archi & 47.25 & 7.96 & 45.65 & 59.60 & 34.60 & 5.95 & 5.75 & 5.35 & 21.70 & 0.15 \\
\hline 12. The Padre Tifirò Church & 46.13 & 7.36 & 46.20 & 59.70 & 34.90 & 5.94 & 5.44 & 5.05 & 19.40 & 0.15 \\
\hline 13. Primary school Corriolo & 13.06 & 4.54 & 12.45 & 19.50 & 4.20 & 4.15 & 3.66 & 3.20 & 11.70 & 0.15 \\
\hline 14. Primary school S. Lucia del Mela & 15.01 & 5.19 & 15.60 & 23.68 & 7.30 & 3.14 & 3.94 & 1.45 & 11.40 & 0.15 \\
\hline 15. Primary school Pace del Mela & 16.64 & 7.95 & 15.50 & 37.28 & 7.80 & 4.41 & 3.94 & 3.05 & 14.50 & 0.15 \\
\hline 16. Primary school Giammoro & 19.09 & 4.49 & 19.75 & 27.30 & 12.44 & 6.46 & 10.65 & 3.25 & 38.10 & 0.15 \\
\hline 17. Primary school Gabbia" & 24.10 & 4.70 & 23.45 & 32.50 & 14.90 & 11.12 & 12.69 & 6.55 & 49.30 & 1.70 \\
\hline 18. Primary school S. Pier Niceto & 12.68 & 3.69 & 12.10 & 19.10 & 7.80 & 3.90 & 3.08 & 3.75 & 10.30 & 0.15 \\
\hline 19. Primary school S. Pier Marina & 20.78 & 8.49 & 17.30 & 33.20 & 11.00 & 4.20 & 4.42 & 3.00 & 14.80 & 0.15 \\
\hline 20. Primary school Condrò & 11.43 & 5.82 & 9.95 & 28.16 & 6.30 & 2.75 & 2.95 & 1.80 & 9.50 & 0.15 \\
\hline 21. Primary school Gualtieri & 10.21 & 7.16 & 7.85 & 31.01 & 4.70 & 4.11 & 4.79 & 2.80 & 16.50 & 0.15 \\
\hline Total & 20.40 & 11.95 & 17.50 & 59.70 & 3.40 & 5.10 & 8.61 & 3.05 & 100.00 & 0.15 \\
\hline
\end{tabular}



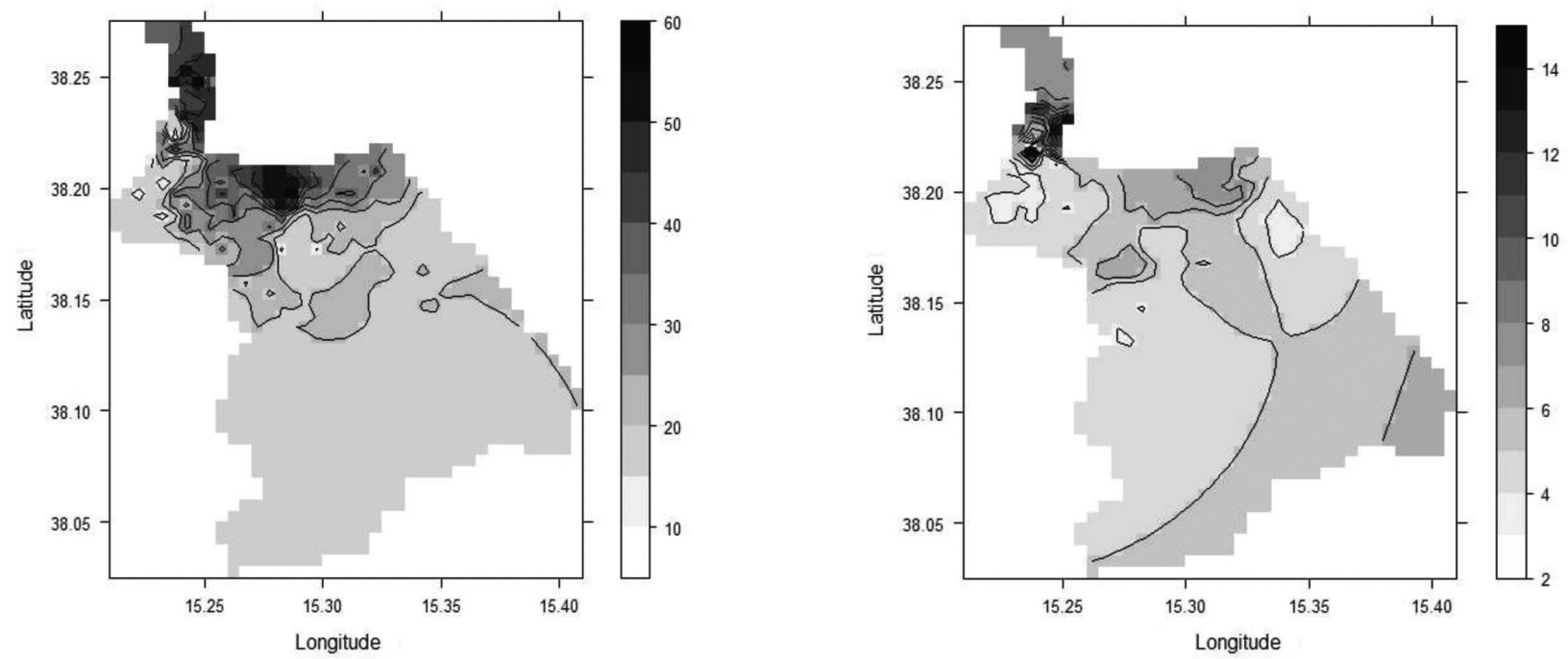

Fig. 4. Spatial distribution of the predicted levels of $\mathrm{NO}_{2}$ (left) and $\mathrm{SO}_{2}$ (right). The Milazzo-Valle del Mela area, November 2007-April 2008.

\section{Predicted exposure levels at the residential addresses}

From the initial sample of children accepting to participate in the study $(2,244 ; 89.5 \%$ of all $), 1,682$ residential addresses were correctly geocoded. The remaining locations were not matched due to missing or incomplete address $(\mathrm{n}=550)$ or they were located outside the study area $(\mathrm{n}=12)$. A mean $\mathrm{NO}_{2}$ exposure level at residential addresses of 25.78 (standard deviation $(\mathrm{SD}): \pm 10.61) \mu \mathrm{g} / \mathrm{m}^{3}$ was estimated, with a maximum of 63.43 and a minimum level of $9.56 \mathrm{\mu g} / \mathrm{m}^{3}$. The predicted concentration at home for 273 children $(12 \%)$ of our study population exceeded the threshold

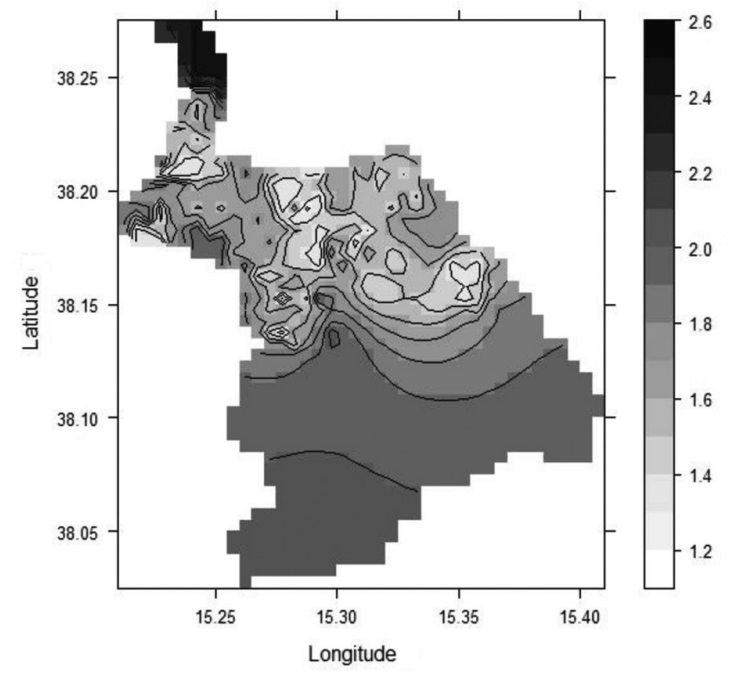

of $40 \mu \mathrm{g} / \mathrm{m}^{3}$ established by both Italian and EU laws (DM n.60 02/04/2002 and Directive 1999/30/EC, respectively). For $\mathrm{SO}_{2}$, we obtained an average predicted level of 4.10 (SD: \pm 2.71$) \mu \mathrm{g} / \mathrm{m}^{3}$ (minimum: 0.61 $\mu \mathrm{g} / \mathrm{m}^{3}$; maximum: $\left.17.05 \mu \mathrm{g} / \mathrm{m}^{3}\right)$. We obtained a Pearson $r$ correlation coefficient between the predicted levels of both pollutants of $0.646(95 \% \mathrm{CI}=0.617$, $0.673)$. The cross-validation process reported a NRMSE for $\mathrm{NO}_{2}$ and $\mathrm{SO}_{2}$ of $28 \%$ and $25 \%$, respectively.

As shown in Fig. 4, higher predicted levels of $\mathrm{NO}_{2}$ were located over the Milazzo city (northwest), the industrial area of the region and along the Palermo-

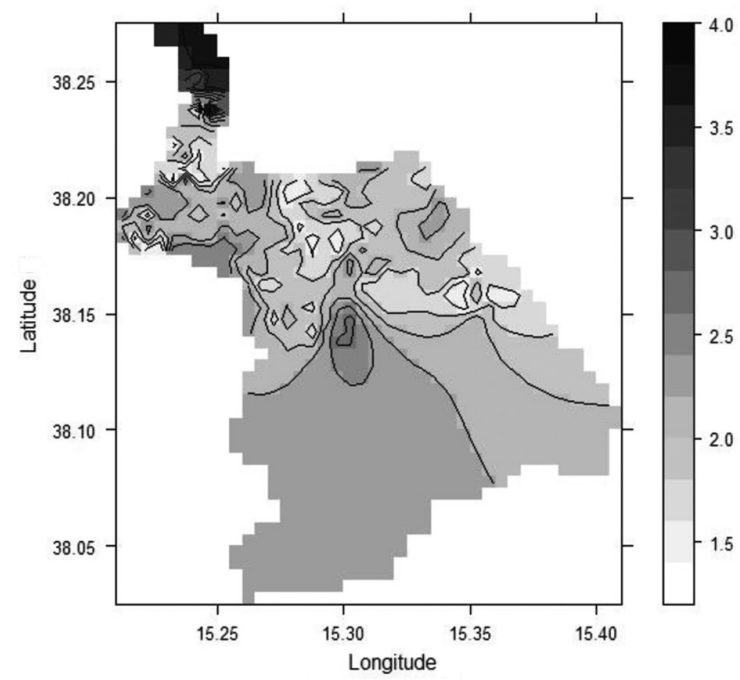

Fig. 5. Spatial distribution of the standard deviation of $\mathrm{NO}_{2}$ (left) and $\mathrm{SO}_{2}$ (right) predicted levels. The Milazzo-Valle del Mela area, November 2007-April 2008. 
Messina highway. Usually, due to its physical and chemical characteristics, this pollutant seems to be located near its main source and does not travel long distances. The highest predicted levels of $\mathrm{SO}_{2}$ correspond again to residences located near the city of Milazzo along with the cape and over the industrial area. Since the median observed values were used in the prediction model, the smoothing pattern was more diffuse for this pollutant with slight differences between the predicted levels of $\mathrm{SO}_{2}$ at each address. Furthermore, one of the main advantages of the kriging approach is that we can also evaluate the level of uncertainty of our prediction by plotting the predicted SD (Fig. 5). According to the figures, the areas with large imprecision were the least populated zones between Santa Lucia and Gualtieri Sicaminò (south) and the border zones of the Capo peninsula (northwest). Children living in these areas (near the schools nos. 14, 18, and 21 and in the apical zone of the cape) account for the $16 \%$ of our study population. Moreover, the Capo area was sampled less intensively since the dosimeters nos. 3 and 4 measured in alternate weeks, i.e. dosimeter 3 registered weeks 1, 3, 5, 7, 9 and 11, while dosimeter no. 4 was active during the remaining weeks.

We observed that children with exposure level of $\mathrm{NO}_{2}$ above the threshold of $40 \mu \mathrm{g} / \mathrm{m}^{3}$ were mostly located near the city of Milazzo and around the industrial area. However, regarding them, the estimations corresponding to the children living in the apical zone of the Milazzo Cape reported a higher uncertainty, with a SD $>1.8$ (which is the $90^{\text {th }}$ percentile of the distribution of the estimates' SD). A similar pattern was observed for $\mathrm{SO}_{2}$, but only the highest exposure levels $\left(>10 \mu \mathrm{g} / \mathrm{m}^{3}\right)$ corresponded to the residences in Milazzo city, but not in the industrial area.

\section{Discussion}

The present study was aimed at estimating the individual exposure of air pollutants for children living in the high-risk area of Milazzo-Valle del Mela. Observed levels of $\mathrm{NO}_{2}$ were $>20 \mu \mathrm{g} / \mathrm{m}^{3}$ and the individual estimated levels of 273 children $(12 \%)$ exceeded the threshold level $\left(40 \mu \mathrm{g} / \mathrm{m}^{3}\right.$ annual mean) established by the Italian and EU laws (DM n.60 02/04/2002 and Directive 1999/30/EC, respectively). Weekly $\mathrm{SO}_{2}$ averages $>20 \mu \mathrm{g} / \mathrm{m}^{3}$ were observed in almost half of the passive dosimeters. Bayesian kriging results showed a strong spatial pattern. In the present study we took advantage of an ad hoc monitoring campaign with passive dosimeters located at each school. This is an advantage with regard to the existing monitoring network in the area because fixed stations are placed in locations where expected pollutant concentrations are high. The use of data from fixed stations would have led to an overestimation of the population exposure. Besides that, we had 21 dosimeters in a region of less than $50 \mathrm{~km}^{2}$, i.e. one dosimeter per $4 \mathrm{~km}^{2}$, which corresponds to grid cells of roughly $2 \times 2 \mathrm{~km}$, a relatively dense network of measurement sites (Briggs, 2005). These locations were also indirectly driven by population density, which is a better solution with respect to a regular grid for the purpose of the study. Not surprisingly, we obtained a NRMSE of $28 \%$ and $25 \%$ for $\mathrm{NO}_{2}$ and $\mathrm{SO}_{2}$, respectively.

In the epidemiological analysis weighting by the predictions uncertainty will provide more robust results.

We considered also covariates in our statistical modelling similar to other approaches in the literature. However, these procedures are essentially two-step approaches so uncertainty estimation is difficult to undertake and rarely done (Hoek et al., 2008). Bayesian geostatistics (Diggle et al., 1998) extend geostatistics to a non-linear function of the spatial Gaussian process and provide more flexible modelling, parameter estimation and sensitivity analysis. In our situation, we used the Bayesian approach to integrate also information from covariates, which cannot be easily handled by standard kriging techniques because of ill-defined design matrices.

We aimed to estimate long-term or cumulative exposure to ambient pollutants, characterising the more exposed residential locations - in fact the observed data were weekly averages. We relied on the fact that the main pollution sources of the area and other elements that could influence the emission, dispersion and distribution of air pollutants (land use, urbanization and climate) were relatively stable in the relevant study period. In other cross-sectional studies in the literature, exposure was assessed by 3-year averages of daily concentrations (Braun-Fahrländer et al., 1997; Akinbami et al., 2010; Penard-Morand et al., 2010; Dong et al., 2011). Other cohort studies have followed a more accurate procedure of measuring exposure at different times during children's life in relation to lung development (Gauderman et al., 2007). Hence, despite the high quality and reliability of the observed data, we should be aware of limitations related to the fact that the passive dosimeter approach gave weekly averages and the analyses were purely spatial.

Additionally, regarding $\mathrm{SO}_{2}$ the median value of the 12 -weekly observed concentrations was used in the 
prediction process. The registered mean levels were highly influenced by some registered peaks that occurred during the campaign period due to local discontinuous pollutant emission sources, which could be not related to the main industrial sources. We preferred not to use the mean estimate, because we wished to control potential measurement error bias by not assigning too much weight to erratic concentration levels. Furthermore, we only studied the effect of ambient levels of $\mathrm{NO}_{2}$ and $\mathrm{SO}_{2}$ as markers of the a priori known industrial and traffic air pollution sources in the study area. We did not take into account other pollutants such as particulate matter and ozone, previously associated with respiratory symptoms. Air pollutants are usually highly correlated because most of them share the same source. In our study, the $\mathrm{NO}_{2}$ and $\mathrm{SO}_{2}$ levels showed a Pearson correlation coefficient of 0.685 . The relatively high correlation between both air pollutants indicates that in this study also $\mathrm{NO}_{2}$ had a relevant contribution from industrial sources and, moreover, the main sources of air pollutants (the Palermo-Messina highway and the industrial area) are located in the same area). It should be mentioned, however, that the study period comprised only the seasons of winter and early spring, so the possible variation of the ambient levels of both air pollutants and their correlation of air pollutants due to seasonality (i.e. meteorological variables) would not be reflected in the observed exposure levels. This fact should also be taken into account when interpreting the results regarding the children with predicted levels above the $\mathrm{NO}_{2}$ EU threshold. This value is an annual mean, whereas in our study we just covered the period of winter and early spring. Therefore both levels cannot be directly compared, and the possible derived conclusions should not be accepted without caution.

Geocoding misclassification cannot be excluded, since the accuracy of the procedure based on the GIS software (in particular the road layout) in the study area was not tested. Errors can arise from several factors such as not correctly updated road layout; possible, positional inaccuracy of the streets which could be affected by the source scale as well as digitizing error; or the accuracy of address information may be wrong or limited. A comparison between the initial geocode and the one obtained with global positioning system (GPS) devices could be of interest in order to evaluate the accuracy of the geocoding process applied in this study.

Time-activity patterns were not assessed. Time spent indoors versus outdoors, and in different parts of the city, would affect real exposure experienced by the study subjects. This would include sources of indoor air pollution and may have more variability than measurements from the outdoor monitoring network. Thus, combining data on activity patterns (such as the time an individual spends in each microenvironment) with estimates of exposure would be important in assessing personal exposure.

\section{Conclusion}

Bayesian kriging represents a useful tool to provide exposure estimates to ambient pollutants at residential addresses. Moreover, the prediction uncertainty is highly informative and can be used both when designing subsequent campaign and for the improvement of modelling epidemiological associations.

\section{Acknowledgements}

The authors would like to gratefully acknowledge the scientific support of the Master in Epidemiology of the University of Turin and by the San Paolo Foundation and the MIUR Research grant 2009JXАBPP.

\section{References}

Akinbami LJ, Lynch CD, Parker JD, Woodruff TJ, 2010. The association between childhood asthma prevalence and monitored air pollutants in metropolitan areas, United States, 2001-2004. Environ Res 110, 294-301.

Anderson HR, Ruggles R, Pandey KD, Kapetanakis V, Brunekreef B, Lai CK, Strachan DP, Weiland SK, ISAAC Phase One Study Group, 2010. Ambient particulate pollution and the world-wide prevalence of asthma, rhinoconjunctivitis and eczema in children: phase one of the International Study of Asthma and Allergies in Childhood (ISAAC). Occup Environ Med 67, 293-300.

Banerjee S, Carlin BP, Gelfand AE, 2006. Hierarchical modeling and analysis for spatial data. Chapman and Hall.

Bell ML, 2006. The use of ambient air quality modeling to estimate individual and population exposure for human health research: a case study of ozone in the Northern Georgia Region of the United States. Environ Int 32, 586-593.

Braun-Fahrländer C, Vuille JC, Sennhauser FH, Neu U, Künzle T, Grize L, Gassner M, Minder C, Schindler C, Varonier HS et al., 1997. Respiratory health and long-term exposure to air pollutants in Swiss schoolchildren. SCARPOL Team. Swiss Study on Childhood Allergy and Respiratory Symptoms with Respect to Air Pollution, Climate and Pollen. Am J Resp Crit Care 155, 1042-1049.

Briggs D, 2005. The role of GIS: coping with space (and time) in air pollution exposure assessment. J Toxicol Environ Health A $68,1243-1261$. 
Brunekreef B, Stewart AW, Anderson HR, Lai CK, Strachan DP, Pearce N, ISAAC Phase 3 Study Group, 2009. Self-reported truck traffic on the street of residence and symptoms of asthma and allergic disease: a global relationship in ISAAC phase 3. Environ Health Perspect 117, 1791-1798.

Chan TC, Chen ML, Lin IF, Lee CH, Chiang PH, Wang DW, Chuang JH, 2009. Spatiotemporal analysis of air pollution and asthma patient visits in Taipei, Taiwan. Int J Health Geogr 7, 8-26.

Cressie N, 2002. Statistics for spatial data. London: Chapman and Hall.

Diggle PJ, Moyeed RA, Tawn JA, 1998. Model-based geostatistics. Appl Statist 47, 299-350.

Dong GH, Chen T, Liu MM, Wang D, Ma YN, Ren WH, Lee YL, Zhao YD, He QC, 2011. Gender differences and effect of air pollution on asthma in children with and without allergic predisposition: northeast Chinese children health study. PLoS One 6, e22470.

Esplugues A, Ballester F, Estarlich M, Llop S, Fuentes-Leonarte V, Mantilla E, Vioque J, Iñiguez C, 2011. Outdoor, but not indoor, nitrogen dioxide exposure is associated with persistent cough during the first year of life. Sci Total Environ 409, 4667-4673.

Gauderman WJ, Vora H, McConnell R, Berhane K, Gilliland F, Thomas D, Lurmann F, Avol E, Künzli N, Jerrett $M$ et al., 2007. Effect of exposure to traffic on lung development from 10 to 18 years of age: a cohort study. Lancet 369, 571-577.

Gelman A, Rubin DR, 1992. Inference from iterative simulation using multiple sequences (with discussion). Stat Sci 7, 457511.

Hastie T, Tibshirani R, Friedman J, 2009. The elements of statistical learning: data mining, inference, and prediction. New York: Springer (second edition).

Heinrich J, Topp R, Gehring U, Thefeld W, 2004. Traffic at residential address, respiratory health, and atopy in adults: the National German Health Survey 1998. Environ Res 98, 240249.

Hoek G, Beelen R, de Hoogh K, Vienneau D, Gulliver J, Fischer P, Briggs D, 2008. A review of land-use regression models to assess spatial variation of outdoor air pollution. Atmos Environ 42, 7561-7578.

Kuehni CE, Strippoli MP, Zwahlen M, Silverman M, 2006. Association between reported exposure to road traffic and res- piratory symptoms in children: evidence of bias. Int J Epidemiol 35, 779-786.

Liu LJ, Koutrakis P, Suh HH, Mulik JD, Burton RM, 1993. Use of personal measurements for ozone exposure assessment: a pilot study. Environ Health Perspect 101, 318-324.

Lunn DJ, Thomas A, Best N, Spiegelhalter D, 2000. WinBUGS - a Bayesian modelling framework: concepts, structure, and extensibility. Stat Comput 10, 325-337.

McConnell R, Berhane K, Yao L, Jerrett M, Lurmann F, Gilliland F, Künzli N, Gauderman J, Avol E, Thomas D et al., 2006. Traffic, susceptibility, and childhood asthma. Environ Health Perspect 114, 766-772.

Pénard-Morand C, Raherison C, Charpin D, Kopferschmitt C, Lavaud F, Caillaud D, Annesi-Maesano I, 2010. Long-term exposure to close-proximity air pollution and asthma and allergies in urban children. Eur Respir J 36, 33-40.

Peng RD, Bell ML, 2010. Spatial misalignment in time series studies of air pollution and health data. Biostatistics 11, 720740.

Pikhart H, Príkazský V, Bobák M, Kríz B, Celko M, Danová J, Pyrl K, Pretel J, 1997. Association between ambient air concentrations of nitrogen dioxide and respiratory symptoms in children in Prague, Czech Republic. Preliminary results from the Czech part of the SAVIAH Study. Small Area Variation in Air Pollution and Health. Cent Eur J Public Health 5, 82-85. Scapellato ML, Canova C, de Simone A, Carrieri M, Maestrelli P, Simonato L, Bartolucci GB, 2009. Personal $\mathrm{PM}_{10}$ exposure in asthmatic adults in Padova, Italy: seasonal variability and factors affecting individual concentrations of particulate matter. Int J Hyg Environ Health 212, 626-636.

Son JY, Bell ML, Lee JT, 2010. Individual exposure to air pollution and lung function in Korea: spatial analysis using multiple exposure approaches. Environ Res 110, 739-749.

Thomas DC, Stram D, Dwyer J, 1993. Exposure measurement error: influence on exposure-disease relationships and methods of correction. Annu Rev Public Health 14, 69-93.

Tolbert PE, Mulholland JA, MacIntosh DL, Xu F, Daniels D, Devine OJ, Carlin BP, Klein M, Dorley J, Butler AJ et al., 2000. Air quality and pediatric emergency room visits for asthma in Atlanta, Georgia, USA. Am J Epidemiol 151, 798-810.

Venn AJ, Lewis SA, Cooper M, Hubbard R, Britton J, 2001. Living near a main road and the risk of wheezing illness in children. Am J Resp Crit Care 164, 2177-2180. 